\title{
Gender specific factors associated with having stopped smoking among in-school adolescents in Ukraine: results from the Global Youth Tobacco Survey 2005
}

Alice Hazemba ${ }^{1}$, Seter Siziya ${ }^{1}$, Adamson S Muula ${ }^{2 *}$ Emmanuel Rudatsikira ${ }^{3}$

\begin{abstract}
Background: The prevalence of cigarette smoking in Ukraine is different between genders and is among the highest in the world. There is need to identify gender-specific factors that are associated with having stopped smoking among adolescents.

Findings: We used data from the Ukraine Global Youth Tobacco Survey 2005. We carried out a backward stepwise logistic regression analysis with having stopped smoking as the outcome.

Altogether, 2800 adolescents reported having ever smoked cigarettes. Overall 64.1\% (63.4\% male, and 65.5\% female) adolescents reported having stopped smoking. Male adolescents who stated that smoking decreases body weight were $25 \%$ more likely, while female adolescents were $9 \%$ less likely to stop smoking. While male adolescents who received support on how to stop smoking from a family member were $7 \%$ less likely, female adolescents were $60 \%$ more likely to stop smoking. Furthermore, while male adolescents who received a lecture on the harmful effects of smoking were 10\% less likely, female adolescents were $9 \%$ more likely to stop smoking. Finally both male and female adolescents who were sure or most probably that they would not smoke a cigarette offered to them by their best friends were more likely, and those adolescents who were sure that smoking is harmful to health were less likely to stop smoking.

Conclusions: Our study has identified some factors that are associated with having quit smoking that are genderspecific. We believe public health programs targeting adolescent smoking should consider these factors in their design and implementation of gender sensitive interventions.
\end{abstract}

\section{Background}

The prevalence of tobacco smoking in Ukraine is among the highest in the world [1,2]. Furthermore, the age of initiation is getting lower [3]. In the Kiev Global Youth Tobacco survey conducted in 1999, 41\% of 13 to 15 year old in-school reported being current cigarette smokers $[4,5]$.

The Health Belief Model (HBM) is a psychological model that aims to explain and predict health-related behaviours. The model focuses on the attitudes and beliefs of individuals [6,7]. One other aspect of the HBM is the role of cues of action such as a lesson in

\footnotetext{
* Correspondence: muula@email.unc.edu

${ }^{2}$ Department of Community Health, University of Malawi, Blantyre, Malawi
}

school or a family member who discusses the harmful effects of smoking with the adolescent. The HBM has been partly used in predicting health behaviour, including smoking, among college students [8]. We used this model to identify factors that we used in the analysis.

While the incidence and prevalence of smoking in Ukraine has been reported to be growing [2], there are limited data on the cessation of smoking among adolescents and more so on gender-specific correlates for stopping smoking. In order to inform smoking prevention programs in Ukraine, we explored the gender-specific correlates of self reported cessation of smoking among adolescents. 


\section{Methods}

\section{Study design and data collection}

Our study involved secondary analysis of cross sectional data from the Ukraine Global School Youth Tobacco Survey (GYTS) conducted in 2005. The GYTS uses a two-stage probability sampling technique, in which schools are the primary sampling units [9]. The core GTYS questionnaire was adapted to the Ukrainian needs and does not match the core questionnaire.

\section{Data analysis}

Our data analysis was restricted to smoking participants and those who had smoked cigarettes but were no longer smokers. Data analysis was performed using SPSS version 14.0 software. A weighting factor was used in the analysis to reflect the likelihood of sampling each student and to reduce bias by compensating for differing patterns of non response. We obtained frequencies as estimation of prevalence of the main outcome (ever having stopped smoking), and other descriptive characteristics of the sample. We report unadjusted odds ratios (OR) from bivariate analyses. We also conducted a backward stepwise logistic regression analysis to estimate the associations between relevant predictor variables and the outcome, and we report adjusted odds ratios (AOR) with their 95\% confidence intervals (CI) from this analysis.

\section{Results}

Data on whether participants who had ever smoked but had stopped smoking cigarettes or were still smokers were available from 2800 out of 7727 participants. Half (50.0\%) of the participants were males, and $35.5 \%$ of the respondents (35.7\% of males, and $35.4 \%$ of females) were of age 14 years. Overall, $60.6 \%$ of the participants (64.2\% males and $56.3 \%$ females) were current smokers and $64.3 \%$ of the adolescents $(63.4 \%$ of males, and $65.5 \%$ of females) reported having stopped smoking cigarettes. The period since they stopped smoking varied from less than 1 month to 3 years or more. Further description of the sample is shown in table 1.

\section{Association of age with stopping smoking}

Compared to adolescents aged 15 years old and older, both male and female adolescents who were of age less than 13 or were 14 years old were less likely to stop smoking, while those who were of age 13 years were more likely to stop smoking cigarettes (Table 2).

\section{Best friend as source for cigarettes}

Both male and female adolescents who would definitely not accept an offer of a cigarette from a close friend to smoke it were more likely to have stopped smoking cigarettes compared to adolescents who would definitely accept an offer of a cigarette from a best friend and smoke it $(\mathrm{AOR}=3.02$ for males and $\mathrm{AOR}=3.62$ for females) as shown in table 3.

\section{Harmful effects of cigarette smoking}

While male adolescents who had a lecture in the previous year of the survey on harmful effects of smoking were $10 \%(A O R=0.90)$ less likely to have stopped smoking, female adolescents were $9 \%(\mathrm{AOR}=1.09)$ more likely to have stopped smoking compared to adolescents who did not have such a lecture. Male adolescents who reported that cigarette smoking decreases body weight were $25 \%(A O R=1.25)$ more likely to stop smoking, while female adolescents were 9\% (AOR = 0.90) less likely to have stopped smoking compared to adolescents who said that cigarette smoking did not affect body weight.

Both male and female adolescents who reported that cigarette smoking is definitely harmful to health were less likely to stop smoking compared to adolescents who were most probably not certain that smoking is harmful to health $(\mathrm{AOR}=0.92$ for males and $\mathrm{AOR}=0.66$ for females). Furthermore, both male and female adolescents who felt that smoking increases boy weight were more likely to stop smoking (Table 4).

\section{Sources of support or advice on how to stop smoking}

Both male and female adolescents who received support or advice on how to stop smoking from a programme or professional were less likely to stop smoking $(\mathrm{AOR}=0.91$ for males, and $\mathrm{AOR}=0.93$ for females), and while male adolescents who received support or advice from a member of the family were less likely to stop smoking $(\mathrm{AOR}=0.93)$, female adolescents were more likely to stop smoking $(\mathrm{AOR}=1.60)$ compared to adolescents who had not ever received support or advice (Table 5).

\section{Discussion}

Our analysis of the Ukraine Global Youth Tobacco Survey 2005 has shown that, unlike among adults [1], there was no gender difference in cigarette smoking. This finding is consistent with previous reports which have indicated that there is no gender difference in tobacco use in Europe and United States [10,11]. Using data from repeat GYTS from 100 sites around the world, Warren et al report that tobacco use among girls is likely increasing [12]. We first present a discussion of factors associated with stopping smoking that were not significantly different between gender, and then present factors associated with stopping smoking that were different between gender. 
Table 1 Description of the sample

\begin{tabular}{|c|c|c|c|}
\hline & $\begin{array}{l}\text { Total } \\
\mathrm{n}^{*}(\%)^{* *}\end{array}$ & $\begin{array}{l}\text { Male } \\
n^{*}(\%)^{* *}\end{array}$ & $\begin{array}{l}\text { Female } \\
n^{*}(\%)^{* *}\end{array}$ \\
\hline \multicolumn{4}{|l|}{ Age (years) } \\
\hline$<13$ & $948(7.7)$ & $448(7.6)$ & $500(7.9)$ \\
\hline 13 & $2422(26.5)$ & $1130(25.2)$ & $1292(27.8)$ \\
\hline 14 & $2516(35.5)$ & $1265(35.7)$ & $1251(35.4)$ \\
\hline $15+$ & $1627(30.2)$ & $841(31.4)$ & $786(29.0)$ \\
\hline \multicolumn{4}{|l|}{ If one of your best friends proposes you a cigarette will you smoke? } \\
\hline For sure, no & $3305(44.0)$ & $1686(45.8)$ & $1619(42.3)$ \\
\hline Most probably, no & $3069(38.0)$ & $1341(33.5)$ & $1728(42.4)$ \\
\hline Most probably, yes & $476(8.0)$ & $272(8.7)$ & $204(7.2)$ \\
\hline For sure, yes & $623(10.1)$ & $367(12.0)$ & $256(8.2)$ \\
\hline \multicolumn{4}{|l|}{ How do you think, in what way does cigarette smoking affect body weight? } \\
\hline Weight increases & $569(8.9)$ & $309(10.0)$ & $260(7.8)$ \\
\hline Weight decreases & $4418(54.9)$ & $2059(52.0)$ & $2359(57.8)$ \\
\hline Weight doesn't change & $2498(36.2)$ & $1305(38.0)$ & $1193(34.5)$ \\
\hline \multicolumn{4}{|l|}{ How do you think, is cigarette smoking harmful for your health? } \\
\hline For sure, yes & $3128(46.3)$ & $1568(45.9)$ & $1560(46.6)$ \\
\hline Most probably, yes & $3490(43.1)$ & $1599(40.5)$ & $1891(45.6)$ \\
\hline For sure, no & $437(5.8)$ & $272(7.7)$ & $165(3.8)$ \\
\hline Most probably, no & $408(4.9)$ & $226(5.9)$ & $182(3.9)$ \\
\hline \multicolumn{4}{|l|}{ Have you ever got a support or advice how to stop smoking? } \\
\hline Yes, in the frame of the programme or from the professional (doctor, nurse or psychologist) & $573(17.3)$ & $351(18.6)$ & $222(15.6)$ \\
\hline Yes, from my friend & $734(24.3)$ & $419(23.7)$ & $315(25.0)$ \\
\hline Yes, from the member of my family & $534(18.6)$ & $342(21.3)$ & $192(15.2)$ \\
\hline Yes, from several sources & $337(13.8)$ & $196(14.1)$ & $141(13.4)$ \\
\hline No & $661(26.1)$ & $334(22.3)$ & $327(30.8)$ \\
\hline
\end{tabular}

*unweighted frequency

**weighted percent

Table 2 Association of age and stopping smoking

\begin{tabular}{llc}
\hline \multicolumn{1}{l}{ Factor } & \multicolumn{1}{c}{$\begin{array}{c}\text { Adjusted Odds Ratio } \\
\text { (95\% Confidence Interval) } \\
\text { Fales }\end{array}$} & \begin{tabular}{l} 
Females \\
\hline Age (years)
\end{tabular} \\
$<13$ & $0.95(0.90,1.00)$ & $0.79(0.72,0.86)$ \\
13 & $1.83(1.76,1.90)$ & $1.97(1.88,2.07)$ \\
14 & $0.84(0.82,0.87)$ & $0.76(0.73,0.79)$ \\
$15+$ & 1 & 1 \\
\hline The analysis adjusted for all factors in tables 3 to 5.
\end{tabular}

Table 3 Associations of source of cigarettes and stopping smoking

\begin{tabular}{|c|c|c|}
\hline \multirow[b]{2}{*}{ Factor } & \multicolumn{2}{|c|}{$\begin{array}{c}\text { Adjusted Odds Ratio } \\
\text { (95\% Confidence Interval) }\end{array}$} \\
\hline & Males & Females \\
\hline \multicolumn{3}{|c|}{ If one of your best friends proposes you a cigarette will you smoke? } \\
\hline For sure, no & $2.93(2.85,3.02)$ & $3.62(3.48,3.76)$ \\
\hline Most probably, no & $1.95(1.89,2.01)$ & $1.69(1.64,1.75)$ \\
\hline Most probably, yes & $0.39(0.38,0.40)$ & $0.39(0.38,0.40)$ \\
\hline For sure, yes & 1 & 1 \\
\hline
\end{tabular}

The analysis adjusted for all factors in tables 2, 4 and 5 .
Both male and female adolescents who were younger were less likely to stop smoking suggesting that this was the age group for experimenting smoking, and those not in favour of the behaviour would have more likely stop smoking immediately. Meanwhile, adolescents who would have continued to smoke would have been less likely to stop smoking at a later age.

There were no gender differences in smoking cessation related to age, being offered a cigarette by a best friend, weight increase, and getting support or advice on how to stop smoking from a professional or friend. Both male and female adolescents who were of age less than 13 or of age 14 years, certain that cigarette smoking is harmful to health, and had received help on quitting smoking from a professional or friend were less likely to have stopped smoking than those who did not. Both male and female adolescents who were of age 13, definitely would not/most probably would not accept cigarettes from a peer, and perceived smoking increases body weight were more likely to stop smoking We believe this is important information that public health policy makers and professionals involved in 
Table 4 Associations of harmful effects of cigarette smoking with stopping smoking

\begin{tabular}{|c|c|c|}
\hline \multirow[b]{2}{*}{ Factor } & \multicolumn{2}{|c|}{$\begin{array}{l}\text { Adjusted Odds Ratio } \\
\text { (95\% Confidence Interval) }\end{array}$} \\
\hline & Males & Females \\
\hline \multicolumn{3}{|c|}{$\begin{array}{l}\text { How do you think, in what way does cigarette smoking affect body } \\
\text { weight? }\end{array}$} \\
\hline Weight increases & $1.11(1.06,1.16)$ & $1.35(1.28,1.42)$ \\
\hline Weight decreases & $1.25(1.22,1.29)$ & $0.91(0.88,0.94)$ \\
\hline Weight doesn't change & 1 & 1 \\
\hline \multicolumn{3}{|c|}{ How do you think, is cigarette smoking harmful for your health? } \\
\hline For sure, yes & $0.92(0.89,0.95)$ & $0.66(0.63,0.69)$ \\
\hline Most probably, yes & $1.24(1.20,1.28)$ & $0.97(0.92,1.01)$ \\
\hline For sure, no & $0.67(0.63,0.72)$ & $1.07(0.99,1.17)$ \\
\hline Most probably, no & 1 & 1 \\
\hline \multicolumn{3}{|c|}{ Have you ever got a support or advice how to stop smoking? } \\
\hline \multicolumn{3}{|c|}{$\begin{array}{l}\text { Did you have a lecture about the harmfulness of the smoking at one o } \\
\text { your lessons for the last academic year? }\end{array}$} \\
\hline Yes & $0.90(0.88,0.92)$ & $1.09(1.05,1.12)$ \\
\hline No & 1 & 1 \\
\hline
\end{tabular}

The analysis adjusted for all factors in tables 2 to 5 .

Table 5 Associations of sources of support or advice on how to stop smoking with stopping smoking

\begin{tabular}{|c|c|c|}
\hline \multirow[b]{2}{*}{ Factor } & \multicolumn{2}{|c|}{$\begin{array}{c}\text { Adjusted Odds Ratio } \\
\text { (95\% Confidence Interval) }\end{array}$} \\
\hline & Males & Females \\
\hline $\begin{array}{l}\text { Yes, in the frame of the } \\
\text { programme or from the } \\
\text { professional (doctor, nurse or } \\
\text { psychologist) }\end{array}$ & $0.91(0.88,0.95)$ & $0.93(0.89,0.97)$ \\
\hline Yes, from my friend & $0.75(0.73,0.78)$ & $0.96(0.93,0.99)$ \\
\hline $\begin{array}{l}\text { Yes, from the member of my } \\
\text { family }\end{array}$ & $0.93(0.90,0.96)$ & $1.60(1.53,1.68)$ \\
\hline Yes, from several sources & $1.37(1.32,1.42)$ & $0.83(0.80,0.87)$ \\
\hline No & 1 & 1 \\
\hline
\end{tabular}

The analysis adjusted for all factors in tables 2 to 4 .

the designing and delivery of interventions aimed to prevent adolescent smoking in Ukraine need to consider in designing interventions that are not gendersensitive.

It is interesting to note that both male and female adolescents who reported that they would definitely not accept a cigarette from a peer were more likely to have stopped smoking that those who would not. One sense, this would suggest that adolescents who are committed to no longer smoke were more successful to have stopped smoking. Alternatively, our finding may suggest that adolescents who have already quit smoking are more likely not to accept a cigarette from a peer than those who are still smoking. Due to the cross sectional design of our study, however, it is not possible to tease out which of the two explanations may be more likely. It is however obvious that comparing adolescents who have stopped smoking to those who are still smoking, those that have stopped smoking reported that they would not accept a cigarette offer from a peer more than those that are still smoking. Smoking cessation programs should seriously consider the role of peers in facilitating continued smoking in adolescents who may wish to quit.

We found that both male and female adolescents who reported having received advice on how to stop smoking from professionals or friends were less likely to stop smoking suggesting that these sources may not have regarded as credible by the adolescents; the reason partly being that some professionals also smoke cigarettes.

Findings from this study indicate that there were gender differences in smoking cessation related to the perception of the effects of smoking on reducing body weight, support or advice on how to stop smoking from a family member or lecture on the harmful effects of smoking. Previous studies have reported gender differences in responses to smoking cessation messages [13] as well as tobacco cessation interventions $[14,15]$.

We also assessed whether the beliefs about the effect of smoking on weight was associated with having quit smoking. In the GYTS survey adolescents had been asked whether they thought that smoking was associated with weight gain or weight loss. Adolescents who believed that smoking makes one's weight decrease were more likely to have stopped smoking among male adolescents, and less likely to have stopped smoking among female adolescents. What does this mean in the context of Ukraine? In many of the Western countries and lately in emerging economies, female adolescents in general perceive themselves to be overweight or heavy. Lean body weight is desirable. In many of these settings also, smoking is perceived as resulting in lean body weight [16-18]. Some female adolescents smoke in order to achieve or maintain a lean body weight $[19,20]$. Different perceptions of body weight may be different between genders and may explain why male adolescents were more likely to stop smoking in favour of a heavy body weight.

The finding that while male adolescents who received support or advice from family members were less likely to stop smoking, and female adolescents were more likely to stop smoking suggest that female adolescents took family members as credible source of information on cessation of smoking while male adolescents did not.

We found that having had a lecture on the harmful effects of smoking was associated with having quit smoking. A meta-analysis of adolescent smoking cessation programs reported by Sussman et al [21] suggested that programs that included a motivation enhancement 
component, cognitive-behavioural techniques, and social influence approaches were more likely to have been successful. These authors also reported that higher quit rates were found in school-based clinic and classroom modalities and in programs consisting of at least 5 quit sessions. This finding is consistent with our finding among female adolescents who were more likely to stop smoking after having had a lecture on harmful effects of smoking. Although we do not have a description of the content, conduct, frequency and number of lectures that had been delivered to adolescents who reported to have had a lecture, it is still heartening to note that having had a lecture on the harmful effects of smoking was associated with less likelihood of having to quit smoking among male adolescents.

\section{Limitations of the study}

Due to the cross sectional nature of the study, it is not possible to confirm whether the factors that were identified as associated with having quit smoking preceded or followed quitting. The study also relied on self-reported history of having quit smoking. We did not verify that the adolescent had indeed quit smoking, for instance by using biomarkers such as exhaled carbon monoxide. We also did not have data on the nature of interventions that adolescents who reported having received help from a health professional obtained. Furthermore, it is unknown whether the adolescents who reported to have stopped smoking actually purposefully stopped the behaviour or just discontinued it.

\section{Conclusions}

We have identified some factors that are associated with having quit smoking that are gender-specific. We suggest that adolescents' smoking cessation programs in Ukraine consider these factors in the design, implementation and evaluation of their gender sensitive programs guided by the FCTC that Ukraine ratified in 2006.

\section{Acknowledgements}

We are grateful to the Centers for Disease Control and Prevention (CDC) for availing the data to us for further analysis. To the country-coordinating team and the students we say thank for your participation and making a study a success.

\section{Author details \\ 'Department of Community Medicine, University of Zambia Medical School, Lusaka, Zambia. ${ }^{2}$ Department of Community Health, University of Malawi, Blantyre, Malawi. ${ }^{3}$ Departments of Global Health, Biostatistics and Epidemiology, School of Public Health, Loma Linda University, California, USA.}

\section{Authors' contributions}

$\mathrm{AH}$ conducted the analysis and took part in the interpretation of the results; SS conceived the analysis plan, reanalysed the data and participated in the interpretation of the results; ASM led the drafting of the manuscript; and ER participated in the interpretation of the results and writing of the manuscript. All authors read and approved the final draft for submission.

\section{Competing interests}

The authors declare that they have no competing interests.

Received: 1 September 2009 Accepted: 16 March 2010

Published: 16 March 2010

\section{References}

1. Webb CP, Bromet EJ, Tintle NL, Schwartz JE, Gluzman SF, Kostyuchenko S, Havenaar JM: Smoking initiation and nicotine dependence symptoms in Ukraine: Findings from the Ukraine World Mental Health survey. Public Health 2007, 121:663-672.

2. Andreeva TI, Krasovsky KS: Changes in smoking prevalence in Ukraine in 2001-2005. Tob Control 2007, 16:202-206.

3. Andreeva TI, Krasovsky KS: Correlates of smoking initiation among young adults in Ukraine: a cross sectional study. BMC Public Health 2007, 7:106.

4. Kiev Global Youth Tobacco Survey Fact Sheet. http://www.aahperd.org/ iejhe/2003_first/files/hill_2.html.

5. Warren CW, Riley L, Asma S, Eriksen MP, Green L, Blanton C, Loo C, Batchelor S, Yach D: Tobacco use by youth: a surveillance report from the Global Youth Tobacco Survey project. Bull World Health Organ 2000, 78:868-876.

6. Glanz K, Rimer BK, Lewis FM: Health Behavior and Health Education. Theory, Research and Practice San Fransisco: Wiley \& Sons 2002.

7. Glanz K, Marcus Lewis F, Rimer BK: Theory at a glance: a guide for health promotion practice Bethesda: National Institute of Health 1997.

8. Von Ah D, Ebert S, Ngamvitroj A, Park N, Kang DH: Predictors of health behaviours in college students. J Adv Nurs 2004, 48:463-474.

9. Centers for Disease Control and Prevention (CDC): Global Youth Tobacco Surveillance, 2000-2007. Surveillance summaries, January 25 MMWR 2008, 57(No. SS-1).

10. Rudatsikira E, Muula AS, Siziya S: Current cigarette smoking among inschool American youth: results from the 2004 National Youth Tobacco Survey. Int J Equity Health 2009, 8:10.

11. Rachiotis G, Muula AS, Rudatsikira E, Siziya S, Kyrlesi A, Gourgoulianis K, Hadjichristodoulou C: Factors associated with adolescent cigarette smoking in Greece: Results from a cross-sectional study (GYTS study). BMC Public Health 2008, 8:313.

12. Warren CW, Lea $V$, Lee $n r$, McKenna M: Change in tobacco use among 13-15 year olds between 1999 and 2008: findings from the Global Youth Tobacco Survey. Glob Health Promot 2009, 16(Suppl):38-40.

13. Toll BA, Salovey P, O'Malley SS, Mazure CM, Latimer A, McKee SA: Message framing for smoking cessation: the interaction of risk and gender. Nicotine Tob Res 2008, 10:195-200

14. Anthenelli RM, Blom TJ, McElroy SL, Keck PE Jr: Preliminary evidence for gender-specific effects of topiramate aid to smoking cessation. Addiction 2008, 103:687-694.

15. Levin RF, Stout JM, Singleton JK, Londrigan M, Feldman HR, McMillan E: Gender's effect on the efficacy of smoking cessation interventions. Nurs Times 2004, 100:32-34.

16. Cheung PC, Ip PL, Lam ST, Bibby H: A study on body weight perception and weight control behaviours among adolescents in Hong Kong. Hong Kong Med J 2007, 13:16-21.

17. Forman-Hoffman $\mathrm{V}$ : High prevalence of abnormal eating and weight control practices among U.S. high-school students. Eat Behav 2004, 5:325-336.

18. Flanagan JR, Bandomir CA: Coming to grips with weight perception: effects of grasp configuration on perceived heaviness. Percept Psychophys 2000, 62:1204-1219.

19. Dowdell EB, Santucci ME: Health risk behavior assessment: nutrition, weight, and tobacco use in one urban seventh-grade class. Public Health Nurs 2004, 21:128-136.

20. Winter AL, de Guia NA, Ferrence R, Cohen JE: The relationship between body weight perceptions, weight control behaviours and smoking status among adolescents. Can J Public Health 2002, 93:362-365.

21. Sussman S, Sun P, Dent CW: A meta-analysis of teen cigarette smoking cessation. Health Psychol 2006, 25:549-557.

doi:10.1186/1756-0500-3-76

Cite this article as: Hazemba et al:: Gender specific factors associated with having stopped smoking among in-school adolescents in Ukraine: results from the Global Youth Tobacco Survey 2005. BMC Research Notes $20103: 76$. 